\title{
Online Learning Effectiveness During the COVID-19 Pandemic: A Case Study of Saudi Universities
}

\author{
Mohammad Mahyoob, Taibah University, Medina, Saudi Arabia \\ (iD) https://orcid.org/0000-0002-6664-1017
}

\begin{abstract}
This paper is set out to explore the students' attitudes towards online learning effectiveness using the Blackboard platform in three Saudi public universities (Taibah, Hail, and Al-Baha) during COVID-19 pandemic. It examines the main learning activities which ensure the achievement of education quality during unprecedented online learning. These activities are online learning preference, efficiency, participation, achievements, success, and assigned assessment tasks. The survey-based questionnaire method was used to elicit students' responses regarding online learning effectiveness. The total number of students who participated in the survey is 333 (entirely regular bachelor's courses in different majors). The main section of the questionnaire contains several questions about leading online learning activities. The coefficient relation of the p-value is highly correlated when tested using Pearson's $r$ and Spearman's. The score of Cronbach's Alpha is 0.93, which indicates (greater internal consistency) an acceptable level of reliability. The overall mean is 0.20 , and the standard deviation for the sample is 0.095 . The findings positively emphasize the significant influence of online learning on students' academic achievements in most learning factors except in an assigned assessment factor, which is still problematic in the online learning process.
\end{abstract}

\section{KEYWORDS}

COVID-19 Pandemic, Learners' Attitudes, Learning Effectiveness, Online Learning, Saudi Universities

\section{INTRODUCTION}

E-learning is the application of electronic devices in learning so that any learning theory can be applied to e-learning (Bognar, 2016). This study investigates learners' attitudes towards e-learning efficiency during COVID-19, so the constructivist and humanistic learning theory is involved in this study. This theory allows learners to be creators of their world and knowledge (Constructivism).

The continuation of education at the tertiary level during the COVID-19 pandemic outbreak forms a real challenge for colleges and universities. The rapid transition to online learning is the best solution to avoid education undisrupted while universities are closed to ensure faculty members' and students' safety. After the World Health Organization declaration on $11^{\text {th }}$ March 2020 that the novel coronavirus outbreak is a pandemic and the social distance is needed, most global educational 
institutes switched to online learning. It was the first time for most learners and teachers to deal with e-learning without prior experience. Over the past decades, online education has been investigated in different phases; online teaching, online learning, campus support staff, course support materials, learning process effectiveness, etc. Recently, digitization has broadened the capacity and impact of e-learning. The emergence of online education as a significant field of education, along with the launch of (massively open online courses) (MOOCs), emphasizes the importance of promoting digital learning outcomes through improved educational strategies (Dede et al. 2018).

The emergence of novel coronavirus COVID-19 in Wuhan, China, and its outbreak globally was a significant public health emergency that forced all the government sectors to take prevention to block the attack of COVID-19 from all the educational institutions, schools, colleges, universities. The lockdown is applied to keep social distance among all society members (China, 2020). As the world is moving to new digital life from different perspectives, for instance, marketing, finance, communication, social services, education is moving slowly towards a digital view. However, the novel coronavirus speeds up the transition of education from physical to virtual classes. Most of the facilities for moving to e-learning are available and quickly start with the internet's growth to the equipment and tools. Online learning is derived from traditional education, where teachers can meet learners face-to-face. However, online learning teachers tried to engage and attract learners' attention in a similar way to a physical classroom (Tschichold et al., 2009). The impact of the previous slow move to online learning is highly enhanced and augmented during COVID-19 quick move to e-learning. The main potential factor of online education is that it crossed the borders, time, and location. The equity of access to online education enables all the community members to be involved in learning to be professional learners while sitting home if they have been guided to invest their time effectively in online education (Sun \& Chen, 2016).

Due to previous well-planned online and blended learning experiences in Saudi colleges and universities, it was easy to switch to online learning during the novel coronavirus crisis. Teachers and students confronted some challenges. Saudi universities were conducting remote teaching for some general courses before COVID 19 emergency using Blackboard platforms. However, the university technical support staff guides and trains the teachers for online education by conducting online workshops and tutorials. At the same time, students are forced to self-train and access online learning. How could the students adapt to this mass change to the online process? Over the past two decades, mobile devices have been integrated into teaching and learning globally Yao-Ting sung et al. 2016. Online education started using the same mobile devices technologies and internet connectivity, facilitating online teaching, and learning smoothly (Yao-Ting sung et al. 2016). Like some other countries, Saudi Arabia has decided to switch to online education to avoid the novel coronavirus's morbidity and make education accessible anywhere and anytime. There is a relationship between teaching and learning effectiveness and the facilitated activities produced by teachers and learners (Seidel \& Shavelson, 2007; Klassen \& Tze, 2014; Ferguson \& Danielson, 2015).

Many methods have been developed to facilitate online learning via mobile learning or educational technology devices, so switching to online learning is not new. The learners' abilities to benefit from online education during COVID-19 depend on their previous online learning experience or mobile learning (Göksu, 2013). The transition to online learning does not appear suddenly. It is started by computer-based learning and the development of technology (Yamamoto, 2011). According to Penuel (2006), the laptops were used in limited learning methods such as writing assignments, searching notes for answer keys using limited applications. However, today online learning opens doors for multiple uses of mobile devices in teaching and learning, starting with teacher-student virtual interaction. Changing instruction online will make education accessible all the time. However, quality assurance for e-learning effectiveness is essential. The effectiveness of e-learning during COVID-19 is a research gap that is inadequately addressed, and the learning outcomes need to be fulfilled. New pedagogical materials and technological enhancement are necessarily required for teaching and learning during such a crisis. The current research attempts to narrow this gap by investigating the significant factors 
affecting online learning effectiveness. The teamwork will not be supported effectively in e-learning. The learners cannot meet each other face to face to discuss specific topics related to the presentations or assignments. However, some learners will adopt self-directed learning by working hard to gain information for issues, especially if the matter is not very popular or cannot be found on the internet or needs students to create his materials. The remaining of the paper is organized as follows. In Section II, research questions are introduced. In section III, related work is explained. In section IV, methodology and data collection are discussed. In section V results and discussion are presented. Finally, the conclusion and future recommendations are given in section VI.

\section{RESEARCH QUESTIONS}

(1) To what extent each of the following factors: efficiency, participation, performance, and assessment, could be fulfilled in online learning during the COVID-19 pandemic?

(2) To what extent are the learners motivated to the continuation of online education?

\section{SIGNIFICANCE OF THE STUDY}

The current study contributes to our knowledge by addressing six important factors about online learning's effectiveness during the recent global pandemic based on learners' perspectives. First, preference of online learning. Second, the efficiency of online learning. Third, participation during online learning. Then, achievements and performance during online learning. Then, the success of online learning and, finally, assessment tasks (the assignments, presentations, examinations, etc.) during online learning.

This study attempts to evaluate how online learning can be effective during the COVID-19 crisis.

The outcomes can be capitalized as guidelines to enhance online learning during pandemics and appeal for developing new learning and assessment methods and modes. Thus, our findings will allow researchers to understand the factors that influence online learning's effectiveness during the recent pandemic in our context and implement similar case studies to support the innovation of new strategies, techniques, and assessment methods.

\section{HISTORY OF E-LEARNING IN KSA}

Nowadays, the COVID-19 pandemic forced most educational institutes in the Arab world to cope with new learning trends and made it mandatory for teachers and learners to equip with the necessary e-learning skills. Saudi government provided all the school education with free learning applications. Saudi colleges and universities have been providing open e-learning platforms and applications for all teachers and learners all over the country.

According to Matar's study (2011), the Middle East universities have a low implementation level of e-learning with an insignificant ratio of electronic courses with low quality and insufficient application of different facilities delivered with current web2.0 applications and essential services. However, in the last ten years, most middle east countries promoted their e-learning system, and internet connectivity has been provided in different areas of these countries. Collaborative solutions have been considered in Saudi Arabia. All Saudi universities use unified e-learning platforms that provided some tools and systems for effective utilization and collaboration. The e-learning systems in Saudi schools, colleges, and universities have been fully activated after the COVID-19 pandemic, and the teachers and learners are effectively engaged.

According to the internet world stats website, Table 1 shows the statistics usage of internet growth and population use of the internet from 2000 to 2016 in Saudi Arabia. 
Table 1. Internet Growth and Population Statistics in Saudi Arabia1:

\begin{tabular}{|l|l|l|l|l|}
\hline YEAR & Users & Population & $\%$ Pop. & Usage Source \\
\hline 2000 & 200,000 & $21,624,422$ & $0.9 \%$ & ITU \\
\hline 2003 & $1,500,000$ & $21,771,609$ & $6.9 \%$ & ITU \\
\hline 2005 & $2,540,000$ & $23,595,634$ & $10.8 \%$ & C+I+A \\
\hline 2007 & $4,700,000$ & $24,069,943$ & $19.5 \%$ & ITU \\
\hline 2009 & $7,761,800$ & $28,686,633$ & $27.1 \%$ & $\underline{\text { ITU }}$ \\
\hline 2010 & $9,800,000$ & $25,731,776$ & $38.1 \%$ & $\underline{\text { ITU }}$ \\
\hline 2012 & $13,000,000$ & $26,534,504$ & $49.0 \%$ & $\underline{\text { IWS }}$ \\
\hline 2016 & $20,813,695$ & $32,157,974$ & $64.7 \%$ & $\underline{\text { IWS }}$ \\
\hline
\end{tabular}

The modernization of the educational process in Saudi Arabia started more than 30 years ago. King Fahad University of Petroleum and Minerals began a project using computer technology in education in 1980. In 1983, the computer science department at King Saud university started using and introducing computers in education and the Faculty of Education at King Fahd University. In 2005-06, the Ministry of Education launched distance education in women's colleges, and the classes were taught via satellite by different universities. The Saudi government has been keeping pace with new educational technology developments and supporting distance education and e-learning. Saudi government played an essential role in the development of education and e-learning in universities. The Ministry of Higher Education launched the committee of e-learning in Saudi Arabia and other higher education institutions of the higher Gulf Cooperation Council for the Arab Gulf States. Saudi government took on the responsibility of distance education and e-learning to overcome the faced obstacles. The government delivered infrastructure for different remote areas and put up the legislation and policies that ensure virtual learning success. the government also recognized certificates issued by centers of distance education in other universities. All these responsibilities enabled Saudi citizens to get benefit from the distance education system.

In the history of distance education in Saudi universities, Al-Imam Muhammad Ibn Saud Islamic university started distance education in 1954 in the faculty of Religious Sciences. After ten years, the faculty of Arabic Language started distance education as well. In the Faculty of Arts and Faculty of Business at King Saud University, distance-learning began in 1978. King Abdelaziz university started distance-learning in 2002. In 2008, the government established the National Center for Distance Education and e-learning. The regulation and laws governing distance education in Saudi Arabia were issued in 2011. Saudi Electronic University was established in 2011 in Riyadh city, offering distance education services in different majors, and these programs are accredited. Nowadays, most Saudi universities offer e-learning and distance education in various programs ${ }^{2}$. The official e-learning platform in all Saudi universities is the Blackboard program.

\section{RELATED WORK}

The existing literature on online education during COVID-19 is limited, whereas a large amount of research exists in online education in general. COVID-19 pandemic compelled schools, colleges, and universities to move to technology-mediated instruction methods using video conferencing, virtual meeting places, and virtual classrooms to maintain education continuity. Many professors lack professional online teaching experience to create perfect online learning; the Saudi universities conducted several workshops and training sessions to qualify all the faculty members for online teaching using Blackboard platforms. 
A considerable amount of literature has been published on distance and online education. Some researchers conducted several studies on the effectiveness and evaluation of online teaching and learning during novel coronavirus disease. Chinese's "Disrupted classes, Undisrupted Learning" initiative, started over the country during the COVID-19 outbreak to make online learning flexible and reach all the learners in China. The book serves as a guideline for instructors during the recent pandemic (Huang et al., 2020).

A study was conducted by Seth (2020) about distance education during COVID-19. He discussed the real challenges which the untrained professors confronted during the quick transition to distance education. This paper is not supported by a field study which revealed that the article provided some suggestions and strategies to be used in the time of sudden online learning. The study provided some guidelines for faculty members about using technology in teaching online. Zhou et al. (2020) conducted a study about a Chinese government campaign during the COVID-19 pandemic under the title "School's Out, but Class's On". The study analyses the background of large-scale online education and its impacts on community and education. Another study by Zhao et al. (2020) explored various teaching platform strategies in a case study of Guiyang No.1 Middle School during the COVID-19 pandemic. The study is discussing ways to stop schools but effectively continue schooling. The authors show the online educational terminologies which are needed while online learning is involved.

Yao et al. (2020) discussed the teachers' role in online teaching during the COVID-19 pandemic. The study compared the recorded video versus live broadcasting for students' performance. The research concluded that live broadcasting where the teacher-student interaction is involved is better, and the students' academic performance is improved. Mahyoob (2020) in his study showed the obstacles and challenges encountered by English language learners (EFL) in online learning during the COVID-19 pandemic. The study results displayed that EFL learners are not happy with online learning due to the confronted technical and academic challenges. Mahdi (2017) performed a metaanalysis study on the effectiveness of mobile learning. The study focused on vocabulary learning using mobile devices. It reviewed 16 articles about the learners' improvement and performance in vocabulary learning using new communication technology. The study concluded a considerable effect of mobile devices in vocabulary learning for both adults and young, but more useful on adults learning vocabularies.

A literature search revealed that limited studies have focused on online learning's effectiveness during the COVID-19 outbreak. Thus, this study is based on field investigation to examine the success and failure of e-learning effectiveness at the time of the novel coronavirus.

\section{METHODOLOGY AND DATA COLLECTION}

\section{Participants}

The number of samples comprised 333 university students with different education majors in a bachelor's degree. The samples were recruited from three different universities in Saudi Arabia. Their ages varied between 19 and 26 (M:22.5; SD: 2.5). The percentage of female students was 51\%, and the rate of male students was $49 \%$. Table 2 displays the variation of participants according to gender, universities, and departments. Students made use of different platforms in online learning during the COVID-19 outbreak. According to their responses, the majority with a percentage of $84.1 \%$, uses the Blackboard platform, and $15.9 \%$ could not use the Blackboard.

\section{DATA COLLECTION}

The data was collected through an online survey employing a distributed questionnaire to the three public universities: Taibah, Hail, and Al-Baha. All the Saudi universities switched to online learning immediately after the Saudi government announced online education activation during disrupted 
Table 2. Sample structure distribution

\begin{tabular}{|l|l|}
\hline Variables & $\mathbf{N}=\mathbf{3 3 3}$ \\
\hline Sex & $51 \%$ \\
Female & $49 \%$ \\
Male & \\
\hline Total & $\mathbf{1 0 0 \%}$ \\
\hline Universities & $70 \%$ \\
Taibah & $15 \%$ \\
Hail & $15 \%$ \\
Al-Baha & \\
\hline Total & $\mathbf{1 0 0 \%}$ \\
\hline Departments & $55 \%$ \\
English & $19.5 \%$ \\
Islamic Studies & $6.6 \%$ \\
Physics & $5.7 \%$ \\
Medical Sciences & $5.4 \%$ \\
Biology & $3.9 \%$ \\
Arabic & $3.3 \%$ \\
Chemistry & 0.6 \\
Others & \\
\hline Total & $\mathbf{1 0 0 \%}$ \\
\hline
\end{tabular}

Classes in all education institutes all over the country due to the COVID-19 global outbreak. The questionnaire was distributed in different departments of undergraduate students of the three mentioned universities. The survey was distributed in April and May 2020 to get responses about students' views and attitudes towards their performance and achievement in online learning during the COVID-19 outbreak in the second semester of the academic year 2019-2020, as displayed in Table 2.

\section{INSTRUMENT AND MEASURES}

Some researchers distributed the survey online using WhatsApp groups to both males and females students. It gives students opportunities to share their attitudes and perceptions about some factors of success and failure of online education activation during disrupted classes but undisrupted learning in Saudi Arabia's colleges and universities by using the Blackboard platform for teaching. It was distributed in the Preparatory year, Arts, Science, and Medical Colleges. Nine departments participated in filling the online survey. The distribution of students was according to their numbers in the departments, and some departments have many students as in English and Islamic Studies.

In contrast, other departments have a few numbers of students as in science and medical departments. The prepared questionnaire was of two sections; the first section was to obtained demographic information about the learners' age, sex, university, and department. The second section was to elicit information about the platform used in online learning (84.1\% could use Blackboard platform and $15.9 \%$ could not use Blackboard), another question about the other types of programs used during online learning as displayed in Figure 2. In section two, the different types of questions, a 5-point Likert scale, were used to elicit the students' perception and views about the following factors: preferences, efficiency, participation, achievements, successfulness, and online learning tasks during the COVID-19 epidemic. 


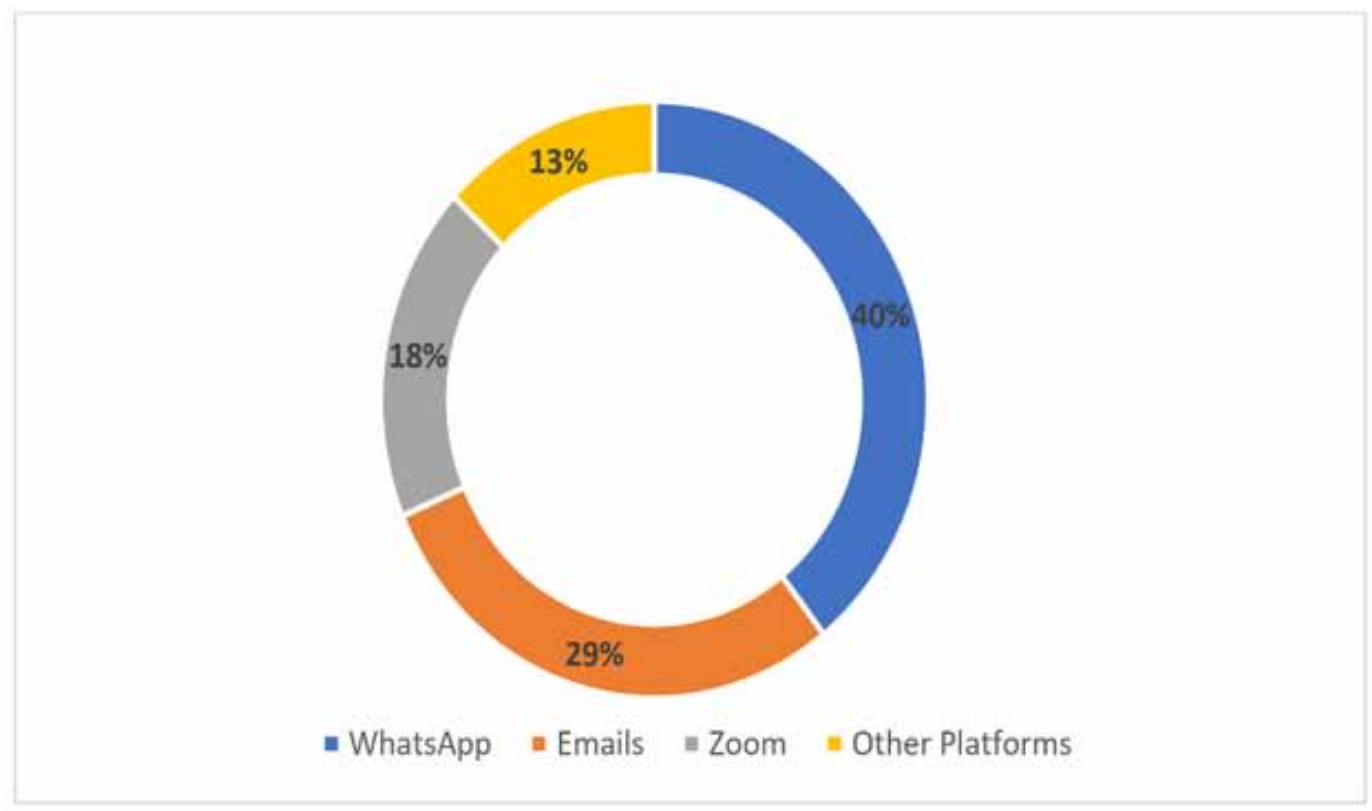

\section{RESULTS AND DISCUSSION}

The teachers and learners use blackboard platforms in Saudi universities to teach some general and elective courses before the COVID-19 crisis. After switching to fully online learning, the universities used the same platform (Blackboard) in online learning. However, some technical issues have been confronted by teachers as well as learners. So, they were compelled to use other learning communication tools to continue in online learning during COVID-19. One of the survey-based questionnaire questions is about other applications that were used during online learning other than Blackboard.

Figure 1 demonstrates the use of other technologies according to the learners' responses; the WhatsApp platform was used by most of the students during online learning with a percentage of $40 \%$ and the second platform is emails with a ratio of $29 \%$. The rate of Zoom Platform uses was $18 \%$. Zoom was used for two reasons; first, learners could not use the Blackboard tool. Second, they were having some problems with Blackboard. Other platforms like Google classroom, Microsoft teams, and other platforms were used with a percentile of $13 \%$.

Table 3 displays the overall samples' responses for the 5-point Likert scale. The following statistical computation and measurements were used in the analysis:

a. Reliability Analysis using the Cronbach alpha value, which was used to test the variables' reliability.

b. Descriptive Analysis is used to analyze the results and check the variations among variables.

c. Correlation using Pearson's and Spearman's scale.

Table 3 displays the students' views and attitudes towards the similarities and differences between classroom-based learning and online learning. It also displays the comparison between Face-to-Face (traditional) and online learning's effectiveness, tasks, activities, etc. from the students' views with the five satisfactions scales (strongly agree, agree, neutral, disagree, strongly disagree) for six factors. 
Table 3. The overall samples' responses for the 5-point Likert scale

\begin{tabular}{|l|l|l|l|l|l|l|l|}
\hline Factors & Total & $\begin{array}{l}\text { Strongly } \\
\text { agree }\end{array}$ & Agree & Neutral & Disagree & $\begin{array}{l}\text { Strongly } \\
\text { Disagree }\end{array}$ & Total \\
\hline $\begin{array}{l}\text { Preference of Online } \\
\text { Learning }\end{array}$ & 333 & $34 \%$ & $11 \%$ & $26 \%$ & $14 \%$ & $15 \%$ & $100 \%$ \\
\hline Efficiency of Online Learning & 333 & $29 \%$ & $16 \%$ & $25 \%$ & $17 \%$ & $14 \%$ & $100 \%$ \\
\hline $\begin{array}{l}\text { Participation during Online } \\
\text { Learning }\end{array}$ & 333 & $36 \%$ & $15 \%$ & $22 \%$ & $16 \%$ & $11 \%$ & $100 \%$ \\
\hline $\begin{array}{l}\text { Improvement during Online } \\
\text { Learning }\end{array}$ & 333 & $37 \%$ & $17 \%$ & $22 \%$ & $13 \%$ & $11 \%$ & $100 \%$ \\
\hline $\begin{array}{l}\text { Successfulness of Online } \\
\text { Learning }\end{array}$ & 333 & $33 \%$ & $14 \%$ & $18 \%$ & $16 \%$ & $20 \%$ & $100 \%$ \\
\hline $\begin{array}{l}\text { Tasks, Assignments and } \\
\text { Examination during Online } \\
\text { Learning }\end{array}$ & 333 & $59 \%$ & $15 \%$ & $15 \%$ & $7 \%$ & $4 \%$ & $100 \%$ \\
\hline
\end{tabular}

Table 4. Reliability analysis of variables

\begin{tabular}{|c|c|c|c|c|c|}
\hline \multirow[b]{2}{*}{ Nr. } & \multirow[b]{2}{*}{ Variables } & \multicolumn{4}{|c|}{ Cronbach's Alpha: 0.93 Valid Cases: 5 Missing Cases: $0(0.0 \%)$} \\
\hline & & $\begin{array}{l}\quad \text { Mean } \\
\text { scale w/o } \\
\text { item }\end{array}$ & $\begin{array}{r}\text { Std.dev. } \\
\text { scale w/o item }\end{array}$ & $\begin{array}{l}\text { Corrected } \\
\text { item scale corr. }\end{array}$ & $\begin{array}{ll}\text { Alpha w/o } \\
\text { item }\end{array}$ \\
\hline 1 & $\begin{array}{l}\text { Preference of Online } \\
\text { Learning }\end{array}$ & 1.00 & 0.55 & 0.91 & 0.92 \\
\hline 2 & $\begin{array}{l}\text { Efficiency of Online } \\
\text { Learning }\end{array}$ & 1.00 & 0.58 & 0.91 & 0.93 \\
\hline 3 & $\begin{array}{l}\text { Participation during } \\
\text { Online Learning }\end{array}$ & 1.00 & 0.54 & 0.99 & 0.91 \\
\hline 4 & $\begin{array}{l}\text { Improvement during } \\
\text { Online Learning }\end{array}$ & 1.00 & 0.53 & 0.98 & 0.90 \\
\hline 5 & $\begin{array}{l}\text { Successfulness of } \\
\text { Online Learning }\end{array}$ & 1.00 & 0.57 & 0.88 & 0.93 \\
\hline 6 & Assigned tasks & 1.00 & 0.42 & 0.94 & 0.97 \\
\hline
\end{tabular}

The first factor is about the preference of online learning; students prefer online learning more than traditional education; the students' responses vary but "strongly agree" scored the highest percentage of $34 \%$. In the second factor, which is about online efficiency, the responses with $29 \%$ are "strongly agree". The third Factor is about participation effectively; students strongly agreed with a $36 \%$ ratio to effective online learning participation. The fourth factor compares the improvement in both modes of learning; $37 \%$ of students strongly agreed to better improvement in online learning. In the fifth factor, $33 \%$ of responses strongly agreed to the success of online learning. The final factor, where the assigned tasks and activities during online learning showed "strongly agree" with a rate of 59\%, as the learners were overloaded and with tasks and examinations during online learning. 
Table 5. Calculation of Descriptive statistics for Learners' responses

\begin{tabular}{|c|c|c|c|c|c|c|c|c|}
\hline & Item & $\mathbf{N}$ & Mean & $\begin{array}{l}\text { Std.dev. } \\
\text { (samp.) }\end{array}$ & $\begin{array}{l}\text { Std.dev. } \\
\text { (pop.) }\end{array}$ & Min. & Median & Max. \\
\hline 1 & Preference of Online Learning & 5 & 0.20 & 0.086 & 0.097 & 0.11 & 0.15 & 0.34 \\
\hline 2 & Efficiency of Online Learning & 5 & 0.20 & 0.058 & 0.065 & 0.14 & 0.17 & 0.29 \\
\hline 3 & $\begin{array}{l}\text { Participation during Online } \\
\text { Learning }\end{array}$ & 5 & 0.20 & 0.087 & 0.098 & 0.11 & 0.16 & 0.36 \\
\hline 4 & $\begin{array}{l}\text { Improvement during Online } \\
\text { Learning }\end{array}$ & 5 & 0.20 & 0.093 & 0.104 & 0.11 & 0.17 & 0.37 \\
\hline 5 & Successfulness of Online Learning & 5 & 0.20 & 0.067 & 0.075 & 0.14 & 0.18 & 0.33 \\
\hline 6 & $\begin{array}{l}\text { Tasks, Assignments and } \\
\text { Examination during Online } \\
\text { Learning }\end{array}$ & 5 & 0.20 & 0.200 & 0.223 & 0.04 & 0.15 & 0.59 \\
\hline & TOTAL SCALE (summation) & 5 & 1.20 & 0.568 & 0.635 & 0.75 & 0.88 & 2.28 \\
\hline & TOTAL SCALE (mean) & 5 & 0.20 & 0.095 & 0.106 & 0.13 & 0.15 & 0.38 \\
\hline
\end{tabular}

\section{RELIABILITY ANALYSIS}

For computing the reliability analysis of the six variables in this study, the Cronbach's Alpha scale and the number of valid and missing cases have been calculated as displayed in Table 4.

Cronbach's Alpha coefficient is more reliable with a 0.93 score. The total number of valid cases is five, and the number of missing cases is 0. Cronbach's Alpha of this study is within the range below one or less than 0.95 , indicating (greater internal consistency). The mean values without the item score are acceptable, and the scale's standard deviation without the item. The corrected scale correlation computes the strength of the thing correlates with the total scale; accordingly, all the items scores very high correlations, so they are suitable for the final ranking. The last column displayed Cronbach's alpha scores for all the variables. They are reliable except one variable, "overloaded tasks, assignments, and examinations," which scores 0.97, which means it is more than Cronbach's Alpha rate (0.93). This item with the highest scale correlation has the correct polarity because it is less than one. It means that there is no conflict with the study assumption for the computation of Cronbach's Alpha.

\section{DESCRIPTIVE ANALYSIS}

The descriptive analysis is used to determine the distribution percentage of calculated values related to the variables. The mean, standard deviation, minimum, maximum, and median are calculated for students' responses as displayed in Table 5:

Table 5 contains the number of valid cases (5), and it highlights the computation of the overall mean $(0.20)$, the standard deviation for sample (0.095), and the standard deviation for the population (0.106). The median is 0.15 , the maximum is 0.38 , and the minimum is 0.13 of all the variables related to online learning during COVID-19, most of the learners in the three Saudi universities preferred online learning.

Figure 2 demonstrates the comparison and distribution of all the evaluated variables; it indicates the distribution of learners' responses, the bold line in the middle suggests median, the bounders of the graphs show the first and the third quartiles, the arms indicate the highest and the lowest data value. So, the longer the bar, the better the output. 
Figure 2. The distribution of studied factors

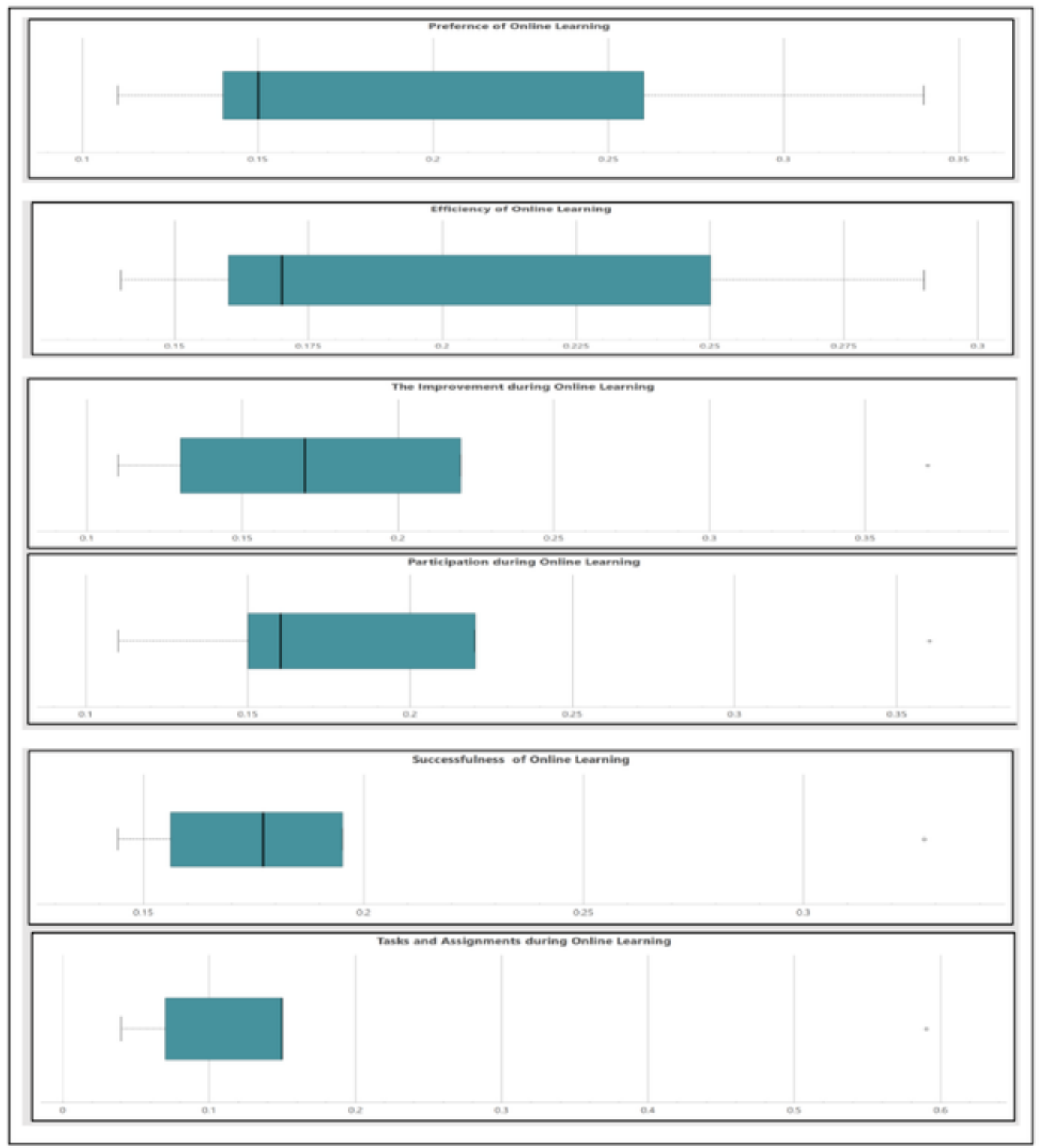

It is observed that the first two factors regarding online learning scored better results (favourability and efficiency) for the effectiveness of online learning. The second two factors indicate average score during online learning (participation and improvement). However, the last two factors distinguish the low score distribution (to some extent, online learning is successful as its score is between 0.15 and 0.2). The final factor (assignments, tasks, and examinations) with the shortest bar indicates the least score below 0.1 and less than 0.15 , i.e., projects, tasks, and examinations are still problematic and require real solutions during online learning. 


\section{CORRELATION}

The correlation between variables can be calculated through the more and the less relationship between variables. To cover the whole relationship, we calculate the bivariate correlations. The two types of calculating the correlations can be carried out using two statistical methods. The first one, which can be usually utilized for interval scale variables, is Pearson's scale, and the second, which is generally used for ordinal scale variables, is Spearman's scale. Both measurements contain the pairwise correlation, the p-value: 2-tailed. The results tables display three types of data:

1. The calculated correlation coefficient.

2. The p-value for the significance of the correlation coefficient.

Tables 6-7 indicate the computation of the p-value: 2-tailed Pearson's and spearman's correlation.

Table 6 shows the Pearson's r correlation between variables; it is highlighted for the small p-value. The table indicates the Correlation of Pearson's $r$ ( $p$-value: 2-tailed) between variables is significantly coefficient except in the last variable (assignment, presentations, examination, and other tasks) where the score is small ( $\mathrm{p}=0.0406)$, so the significance correlation is not coefficient.

Table 6. Correlation: Pearson's r (p-value: 2-tailed)

\begin{tabular}{|l|l|}
\hline Variables & $\begin{array}{l}\text { Effectiveness of Online Learning } \\
\text { during COVID-19 Pandemic }\end{array}$ \\
\hline Preference of Online Learning & $0.855(\mathrm{p}=0.0646) \mathrm{N}=5$ \\
\hline The efficiency of Online Learning & $0.737(\mathrm{p}=0.1550) \mathrm{N}=5$ \\
\hline Participation during Online Learning & $0.853(\mathrm{p}=0.0661) \mathrm{N}=5$ \\
\hline Improvement during Online Learning & $0.844(\mathrm{p}=0.0722) \mathrm{N}=5$ \\
\hline $\begin{array}{l}\text { Tasks, Assignments, and Examination } \\
\text { during Online Learning }\end{array}$ & $0.894(\mathrm{p}=0.0406) \mathrm{N}=5$ \\
\hline
\end{tabular}

Table 7 displays the statistical computation of Spearman's 2-tailed test of the p-value. All the variables are significantly correlated, and the coefficient and the scores are between 0.5 and 0.95 , which are positively correlated.

The findings positively ensure the efficiency and effectiveness of online learning and its influence on students' academic performance in all the learning factors except the examinations'

Table 7. Correlation: P-value: 2-tailed (Spearman)

\begin{tabular}{|l|l|}
\hline Variables & $\begin{array}{l}\text { Effectiveness of Online Learning during } \\
\text { COVID-19 Pandemic }\end{array}$ \\
\hline Preference of Online Learning & $0.900(\mathrm{p}=0.0833) \mathrm{N}=5$ \\
\hline The efficiency of Online Learning & $0.400(\mathrm{p}=0.5162) \mathrm{N}=5$ \\
\hline Participation during Online Learning & $0.400(\mathrm{p}=0.5162) \mathrm{N}=5$ \\
\hline Improvement during Online Learning & $0.300(\mathrm{p}=0.6826) \mathrm{N}=5$ \\
\hline $\begin{array}{l}\text { Tasks, Assignments, and Examination during } \\
\text { Online Learning }\end{array}$ & $0.205(\mathrm{p}=0.6826) \mathrm{N}=5$ \\
\hline
\end{tabular}


and assignments' factors, which are still problematic in the e-learning process. The results of the study support the evidence that online learning can be effective and successful. Students' responses are very positive, and they are fully supporting the transition to online learning, but they did not support the assignments, examinations, and other tasks' factor. Classroom-based learning methods need developing, changing, and updating to be suitable for online learning. Students loved online learning, and they supported its continuation. Most of the learners did not have any experience with online learning before the novel coronavirus outbreak. Still, their reactions to online learning were positive, and they were motivated to e-learning during the second semester of the academic year 2019/ 2020. According to some learners' responses, on the one hand, online learning pushed them to work hard and try to understand the information, to write the assignments by self-directed methods. On the other hand, learners prefer classroom-based learning, as they can be motivated to learn more and better understand. Most students' main issue was the examinations, assignments, and other assessment methods during online learning.

These findings enhance our understanding that alternative methods and strategies are required to investigate and tackle these issues.

\section{LIMITATION OF THE STUDY}

This study is limited to learners of Public Saudi universities. More research is needed for teachers' and administrators' attitudes towards the effectiveness of e-learning. More research is recommended and required in more public universities, private colleges, and schools to measure and evaluate the e-learning process. This research was conducted at the COVID-19 time, so more research is needed to evaluate the effectiveness of e-learning in Saudi institutes during ordinary situations. More research using different instruments like interviews, observations, testing, and using some other instruments is necessary as this study was conducted using a survey-based method.

\section{CONCLUSION AND FUTURE RECOMMENDATION}

The purpose of the current study was to determine the learners' attitudes and assessments towards online learning activities to evaluate online education's effectiveness during the COVID-19 pandemic. Interestingly, the correlation between the independent variable and dependent variables is positive. The analysis revealed that the differences in factors' scores are positively correlated in students' assessments towards online preference, efficiency, success, and participation during online learning, whereas negatively correlated in terms of assignments, tasks, and examinations. The most critical finding from this study is that Pearson's $r$ score was low, related to assignments, examinations, and other online learning tasks. This factor did not show correlation with other elements. The scores of Spearman's tests between all the factors were correlated positively. The p-value scores are significantly the same in terms of online learning's preference, efficiency, success, and participation.

In contrast, they are significantly different in terms of assignments, tasks, and examinations according to Cronbach's score. This paper highlighted the students' perception of the effectiveness of online learning during the COVID-19 pandemic. It crystallized our plan towards the change in teaching and learning methods is required to enhance and make online learning successful. It is time to investigate the difficulties and challenges that learners and teachers encounter during the transition to a new mode of education, which will be future research. 


\section{REFERENCES}

Bennett, S., Killen, C., \& Marsh, D. (2007). Handbook of online education. Bloomsbury Publishing.

Bognar, B. (2016). Theoretical backgrounds of e-learning. Croatian Journal of Education: Hrvatski časopis za odgoj I obrazovanje, 18(1), 225-256.

China, X. (2020). Xi Jinping's “2:23” Important Speech: The "Episode” Program Aiming for Victory. Http:// www.xinhuanet.com/politics/2020- 02/25/c_1125625675.htm,02-23/2020-03-11

Dede, C., Richards, J., \& Saxberg, B. (Eds.). (2018). Learning Engineering for Online Education: Theoretical Contexts and Design-based Examples. Routledge. doi:10.4324/9781351186193

Ferguson, R. F., \& Danielson, C. (2015). How framework for teaching and tripod 7Cs evidence distinguish key components of effective teaching. In Designing teacher evaluation systems: New guidance from the measures of effective teaching project. John Wiley \& Sons.

Göksu, İ., \& Atici, B. (2013). Need for mobile learning: Technologies and opportunities. Procedia: Social and Behavioral Sciences, 103, 685-694. doi:10.1016/j.sbspro.2013.10.388

Huang, R. H., Liu, D. J., Tlili, A., Yang, J. F., \& Wang, H. H. (2020). Handbook on facilitating flexible learning during educational disruption: The Chinese experience in maintaining undisrupted learning in covid-19 outbreak. Smart Learning Institute of Beijing Normal University.

Klassen, R. M., \& Tze, V. M. (2014). Teachers' self-efficacy, personality, and teaching effectiveness: A metaanalysis. Educational Research Review, 12, 59-76. doi:10.1016/j.edurev.2014.06.001

Kleickmann, T., Richter, D., Kunter, M., Elsner, J., Besser, M., Krauss, S., \& Baumert, J. (2013). Teachers' content knowledge and pedagogical content knowledge: The role of structural differences in teacher education. Journal of Teacher Education, 64(1), 90-106. doi:10.1177/0022487112460398

Mahdi, H. S. (2018). Effectiveness of mobile devices on vocabulary learning: A meta analysis. Journal of Educational Computing Research, 56(1), 134-154. doi:10.1177/0735633117698826

Mahyoob, M. (2020). Challenges of e-Learning during the COVID-19 Pandemic Experienced by EFL Learners. Arab World English Journal, 11(4), 351-362. doi:10.24093/awej/vol11no4.23

Matar, N., Hunaiti, Z., Halling, S., \& Matar, Š. (2011). E-Learning acceptance and challenges in the Arab region. In ICT acceptance, investment, and organization: Cultural practices and values in the Arab world (pp. 184-200). IGI Global. doi:10.4018/978-1-60960-048-8.ch013

Nakayama, M., Yamamoto, H., \& Santiago, R. (2011). Online learning management and learners' behavior: A case study of online learning in Japan. In Developing and utilizing e-learning applications (pp. 155-174). IGI Global. doi:10.4018/978-1-61692-791-2.ch009

Nakayama, M., \& Yamamoto, H. (2011). Assessing Student Transitions in an Online Learning Environment. Electronic Journal of e-Learning, 9(1), 75-86.

Oranburg, S. (2020). Distance Education in the Time of Coronavirus: Quick and Easy Strategies for Professors. Duquesne University School of Law Research Paper No. -02. Available at https://ssrn.com/ abstract $=355391110.2139 / \mathrm{ssrn} .3553911$

Penuel, W. R. (2006). Implementation and effects of 1:1 computing initiatives: a research synthesis. Journal of Research on Technology in Education, 38, 329-348. .10.1080/15391523.2006.10782463

Seidel, T., \& Shavelson, R. J. (2007). Teaching effectiveness research in the past decade: The role of theory and research design in disentangling meta-analysis results. Review of Educational Research, 77(4), 454-499. doi:10.3102/0034654307310317

Sun, A., \& Chen, X. (2016). Online education and its effective practice: A research review. Journal of Information Technology Education, 15, 15. doi:10.28945/3502

Sung, Y. T., Chang, K. E., \& Liu, T. C. (2016). The effects of integrating mobile devices with teaching and learning on students' learning performance: A meta-analysis and research synthesis. Computers \& Education, 94, 252-275. doi:10.1016/j.compedu.2015.11.008 
Tschichold, C. (2009). Online Communication in Language Learning and Teaching. Palgrave Macmillan.

YaoJ.RaoJ.JiangT.XiongC. (2020). What Role Should Teachers Play in Online Teaching during the COVID-19 Pandemic? Evidence from China. Sci Insight Edu Front, 5(2), 517-524. https://ssrn.com/abstract=3565608

Zhao, N., Zhou, X., Liu, B., \& Liu, W. (2020). Guiding Teaching Strategies with the Education Platform during the COVID-19 Epidemic: Taking Guiyang No. 1 Middle School Teaching Practice as an Example. Sci Insigt Edu Front, 5(2), 531-539. Available at https://ssrn.com/abstract=356562510.2139/ssrn.3565625

ZhouL.WuS.ZhouM.LiF. (2020). 'School's Out, But Class' On', The Largest Online Education in the World Today: Taking China's Practical Exploration During The COVID-19 Epidemic Prevention and Control As an Example. Best Evid Chin Edu, 4(2), 501-519. Available at https://ssrn.com/abstract=355552010.2139/ssrn.3555520

\section{ENDNOTES}

https://www.internetworldstats.com/me/sa.htm

https://elearnmag.acm.org/archive.cfm?aid=2673861

Mohammad Mahyoob is currently working as an Assistant Professor in the Department of Languages \& Translation, College of Science and Arts, Alula, Taibah University, Madina, Saudi Arabia. He holds PhD in Computational Linguistics. His research interests include Theoretical and Applied Linguistics, Computational Linguistics and e-learning. 